\title{
Awareness of Birth Preparedness and Complication Readiness in Southeastern Nigeria
}

\author{
John E. Ekabua, ${ }^{1}$ Kufre J. Ekabua, ${ }^{2}$ Patience Odusolu, ${ }^{1}$ Thomas U. Agan, ${ }^{1}$ \\ Christopher U. Iklaki, ${ }^{1}$ and Aniekan J. Etokidem ${ }^{2}$ \\ ${ }^{1}$ Department of Obstetrics \& Gynecology, University of Calabar Teaching Hospital, Calabar P.M.B 1278, Calabar, \\ Cross River State, Nigeria \\ ${ }^{2}$ Department of Community Medicine, University of Calabar Teaching Hospital, Calabar P.M.B 1278, Calabar, \\ Cross River State, Nigeria
}

Correspondence should be addressed to John E. Ekabua, johnekabua@yahoo.com

Received 11 April 2011; Accepted 18 May 2011

Academic Editor: E. Cosmi

Copyright ( 92011 John E. Ekabua et al. This is an open access article distributed under the Creative Commons Attribution License, which permits unrestricted use, distribution, and reproduction in any medium, provided the original work is properly cited.

\begin{abstract}
The aims of this study are to assess the awareness and intention to use maternity services. This was a multicentric study involving 800 women. Educational status was the best predictor of awareness of birth preparedness $(P=0.0029)$, but not a good predictor of intention to attend four antenatal clinic sessions $(P=0.449)$. Parity was a better predictor of knowledge of severe vaginal bleeding as a key danger sign during pregnancy than educational level $(P=0.0009$ and $P=0.3849$, resp. $)$. Plan to identify a means of transport to the place of childbirth was related to greater awareness of birth preparedness $\left(\chi^{2}=0.3255 ; P=0.5683\right)$. Parity was a highly significant predictor $(P=0.0089)$ of planning to save money. Planning to save money for childbirth was associated with greater awareness of community financial support system $\left(\chi^{2}=0.8602 ; P=0.3536\right)$. Access to skilled birth attendance should be promoted.
\end{abstract}

\section{Introduction}

The principle and practice of birth preparedness and complication readiness (BP/CR) in a third world setting where there is prevailing illiteracy, inefficient infrastructure, poor transport system, and unpredictable access to skilled care provider have the potential of reducing the existing high maternal and neonatal morbidity and mortality rates. $\mathrm{BP} / \mathrm{CR}$ promotes skilled care for all births and encourages decision making before the onset of labor [1]. The BP/CR matrix raises awareness of danger signs, thereby improving problem recognition and reducing delay in deciding to seek care [2]. It provides information on appropriate sources of care (promoters and facilities) making the care-seeking process more efficient. It also encourages households and communities to set aside money for transport and service fees, avoiding delays in reaching care caused by the search for funds. However, antenatal care in Nigeria is provided along the lines of the traditional approach based on risk assessment and not on the goal-oriented interventions of focused antenatal care, which include BP/CR [3]. The study is a needs assessment designed to determine the level of awareness, attitude and behavior of women to birth preparedness, and complication readiness.

\section{Method}

2.1. Study Area. This cross-sectional, multicentric descriptive study was carried out in Calabar and Biase Local Government Areas of Cross River State, Nigeria. Calabar is the capital of Cross River State. It is made up of two Local Government Areas (LGAs) and 22 geopolitical wards. The total population for this area is 418,652 with majority of the workforce being in government employment or involved in small-scale business ventures. The area hosts a Teaching Hospital, one General Hospital, several maternal and child health centers, and several private hospitals. Biase Local Government Area has an area of $1,310 \mathrm{~km}^{2}$ and a population of 169,183 . Apart from Akpet Central, which is the local government headquarters, the rest of the area is rural. 
2.2. Subjects and Method. A cross-sectional survey of 800 women, who gave birth between 1st January and 31st December 2008, attending two urban (Calabar) and two rural (Biase Local Government Area) maternal and child health clinics in Cross River State, Nigeria, was undertaken between January and April, 2009. Informed oral consent was sought and obtained from participants before inclusion in the study. After due explanation of the study and necessary clarifications of issues raised, the field assistants distributed the questionnaires to the women surveyed. The women were assured of confidentiality and that their names will not be published in the report. The self-administered structured questionnaires were retrieved after two weeks at each study center by field assistants. The study design fulfilled the requirements set by the ethics committee of the Cross River State Ministry of Health. The number of questionnaires returned was 776, giving a survey response rate of $97 \%$. Incorrect or incomplete entries on the questionnaires were excluded from analysis. Data obtained were analyzed using epi info 2002 software, with logistic regression/test of association performed. Information obtained included sociodemographic characteristics; history of last confinement; danger signs in last pregnancy; awareness of birth preparedness and key danger signs; intention of service use; and knowledge of available community support systems. Knowledge of key danger signs and available community support system were assessed according to the proportion of women who correctly answered the relevant questions as follows: excellent: $>80 \%$; good: $60 \%$ to $<80 \%$; poor: $>30 \%$ but $<60 \%$; very poor: $<30 \%$. follows.

For clarity, some terms used in this paper are defined as

(i) Birth preparedness and complication readiness (BP/ $C R$ ) [2] is the process of planning for normal birth and anticipating the actions needed in case of an emergency.

(ii) BP/CR matrix [2] delineates the roles (plans/actions) of policymakers, facility managers, care providers, communities, families, and women in ensuring that women and newborns receive timely appropriate and effective care.

(iii) Skilled care provider/attendant [4] is a professional caregiver who has the knowledge and skills to manage labor, childbirth, and postpartum period; recognize complications; diagnose, manage, or refer woman or newborn to a higher level of care if complications occur that require interventions beyond current caregiver's competence.

(iv) Postpartum period is defined as beginning after delivery of the placenta to 6 weeks after birth.

(v) Newborn/neonatal period refers to the first 7 days of the newborn's life.

(vi) Risk factor [5] is defined as one link in a chain of associations leading to an illness or an indicator of link; and is identifiable prior to the event it predicts.

(vii) Community emergency response mechanism [6] the community is defined as having an emergency
TABLE 1: Sociodemographic characteristics.

\begin{tabular}{lcc}
\hline Variable $(n=$ number $)$ & Number & Percent $(\%)$ \\
\hline Age group $(n=760)$ & 72 & \\
$\quad<20$ years & 604 & 79.4 \\
$20-39$ & 84 & 11.1 \\
$40-49$ & & \\
\hline Marital status $(n=740)$ & 120 & 16.2 \\
$\quad$ Never married & 584 & 78.9 \\
Married & 12 & 1.6 \\
Widow & 24 & 3.2 \\
Separated/divorced & & \\
\hline Educational status $(n=744)$ & 28 & 3.8 \\
No formal education & 204 & 27.4 \\
Primary education & 408 & 54.8 \\
Secondary education & 104 & 14.0 \\
Tertiary education & & \\
\hline Parity $(n=724)$ & 160 & 22.1 \\
1 & 448 & 61.9 \\
$2-4$ & 116 & 16.0 \\
\hline 4
\end{tabular}

response mechanism if all of the following systems are in place: identification of pregnant women, finance, transportation, blood donation, and at least one contact person responsible for linking these systems to the women in need.

\section{Results}

Table 1. The sociodemographic profile of women surveyed showed that $79.4 \%$ were aged $20-39$ years; $78.9 \%$ were married; $54.8 \%$ had secondary education; $61.9 \%$ were para $2-4$.

Tables 2 and 3. The proportion of women residing in the rural area was $55.1 \%$. Hospital delivery was recorded in $48.8 \%$. The commonest means of transport in last confinement was the motorcycle $(64.7 \%)$. The commonest danger signs experienced were as follows: in last pregnancy, prolonged labor (22.4\%); in the baby, stillbirth (5.2\%); after delivery, severe vaginal bleeding (19.1\%). Log regression data showed that residence was a good predictor of the place of last confinement. Women who resided in urban areas were more likely to deliver in the hospital than those who resided in rural areas $\left(\chi^{2}=24.038 ; P<0.0001\right)$. None of the women delivering outside the hospital received skilled attention. Women who were in labor for more than 24 hours were more likely to undergo caesarean section than those who were in labor for less than 12 hours; however, this difference was not statistically significant $\left(\chi^{2}=4.5440\right.$; $P=0.3374)$. Women who were in labor for more than 24 hours were more likely to notice difficult/fast breathing in their babies than those who were in labor for 12 to 24 hours; however, this difference was not statistically significant $\left(\chi^{2}=\right.$ $1.4217 ; P=0.4912)$. 
TABLE 2: History of last confinement.

\begin{tabular}{|c|c|c|}
\hline History/event & Frequency & Percent $(\%)$ \\
\hline \multicolumn{3}{|l|}{ Residence $(n=748)$} \\
\hline Urban & 336 & 44.9 \\
\hline Rural & 412 & 55.1 \\
\hline \multicolumn{3}{|c|}{ Place of last confinement (760) } \\
\hline Hospital & 368 & 48.4 \\
\hline Church & 128 & 16.8 \\
\hline TBA & 148 & 19.5 \\
\hline Home & 116 & 15.3 \\
\hline \multicolumn{3}{|c|}{$\begin{array}{l}\text { Approximate distance from hospital } \\
(n=696)\end{array}$} \\
\hline$<2 \mathrm{~km}$ & 344 & 49.5 \\
\hline $2-5 \mathrm{~km}$ & 296 & 42.5 \\
\hline$>5 \mathrm{~km}$ & 56 & 8.0 \\
\hline \multicolumn{3}{|c|}{ Means of transport $(n=736)$} \\
\hline Taxi & 72 & 9.8 \\
\hline Bus & 44 & 6.0 \\
\hline Motor cycle & 476 & 64.7 \\
\hline Boat & 8 & 1.1 \\
\hline Trekking & 124 & 16.8 \\
\hline Others & 12 & 1.6 \\
\hline Non response & 72 & 9.8 \\
\hline \multicolumn{3}{|c|}{ Duration of labour $(n=736)$} \\
\hline$<12$ hours & 468 & 63.6 \\
\hline 12-24 hours & 204 & 27.7 \\
\hline$>24$ hours & 64 & 8.7 \\
\hline \multicolumn{3}{|c|}{ Mode of delivery $(n=716)$} \\
\hline Vaginal & 620 & 86.6 \\
\hline Episiotomy & 32 & 4.5 \\
\hline Caesarean section & 64 & 8.9 \\
\hline Instrumental & 0 & 0.0 \\
\hline
\end{tabular}

Table 4. Although awareness of the concept of birth preparedness was high (70.6\%), knowledge of specific key danger signs was poor. Logistic regression analysis showed that of the four variables, age, educational status, marital status, and parity, educational status was the best predictor of awareness of the concept of birth preparedness $(P=0.5477$; $0.0029 ; 0.6455 ; 0.4433$, resp.). The place of residence, urban or rural, was not a good predictor of awareness of birth preparedness $\left(\chi^{2}=0.3316 ; P=0.5646\right)$. Parity was a better predictor of knowledge of severe vaginal bleeding as a key danger sign during pregnancy than educational level $(P=$ 0.0009 and $P=0.3849$, resp.).

Table 5. Intention and behavior as regards plan to use maternity services during pregnancy and access skilled attendance in childbirth was generally positive (ranging from 69.5\% to $83.5 \%$ ). However, log regression analysis showed that educational level, marital status and parity were not good predictors of intention and behavior, especially regarding
TABLE 3: Danger signs experienced in last pregnancy.

\begin{tabular}{lcc}
\hline Variable & Frequency & Percent $(\%)$ \\
\hline Danger signs during pregnancy & & \\
Severe vaginal bleeding $(n=760)$ & 84 & 11.1 \\
Swollen hands and feet $(n=760)$ & 96 & 12.6 \\
Blurred vision $(n=752)$ & 104 & 13.8 \\
Prolonged labor $(n=768)$ & 172 & 22.4 \\
Convulsions $(n=752)$ & 32 & 4.3 \\
Retained placenta $(n=760)$ & 56 & 7.4 \\
\hline Problems with baby & & \\
Stillborn $(n=764)$ & 40 & 5.2 \\
Died within 7 days $(n=760)$ & 20 & 2.6 \\
Convulsions/spasms/rigidity $(n=760)$ & 16 & 2.1 \\
Difficult/fast breathing $(n=764)$ & 32 & 4.2 \\
Very small baby $(n=756)$ & 28 & 3.7 \\
Lethargy/unconsciousness $(n=756)$ & 16 & 2.1 \\
\hline Danger signs after delivery & & \\
Severe vaginal bleeding $(n=752)$ & 144 & 19.1 \\
Foul lochia $(n=744)$ & 12 & 1.6 \\
High fever $(n=720)$ & 40 & 5.6 \\
\hline
\end{tabular}

plan to attend at least four antenatal clinic (ANC) visits with a skilled provider $(P=0.449 ; 0.1286$ and 0.9765 , resp.). Those who were aware of birth preparedness were more likely to plan to identify mode of transport to the place of childbirth than those who were not aware. This difference was not statistically significant $\left(\chi^{2}=0.3255\right.$; $P=0.5683$ ). When planning to save money for childbirth was regressed on marital status, educational level, awareness of birth preparedness, and parity, it was observed that parity was a highly significant predictor $(P=0.0089)$ of planning to save money followed by awareness of birth preparedness $(P=0.0101)$. Marital status and level of education were not good predictors of planning to save money for childbirth $(P=0.2394,0.2013$, resp. $)$. Women who planned to save money for child birth were more aware of community financial support system than those who did not plan to save money. This difference was not statistically significant $\left(\chi^{2}=0.8602 ; P=0.3536\right)$. Knowledge of availability of community support systems was very poor among women surveyed.

\section{Discussion}

Birth preparedness and complication readiness (BP/CR) is the process of planning for normal birth and anticipating the actions needed in case of an emergency [2]. Responsibility for BP/CR must be shared among all safe motherhood stakeholders-policymakers, facility managers, providers, communities, families, and women-because a coordinated effort is needed to reduce the delays that contribute to maternal and newborn deaths. Women and newborns need timely access to skilled care during pregnancy, childbirth, and the postpartum/newborn period. Too often, however, their access to care is impeded by delays-delays in deciding to 
TABLE 4: Knowledge of specific danger signs.

\begin{tabular}{lcc}
\hline Knowledge of variable & Frequency & $\begin{array}{c}\text { Percent } \\
(\%)\end{array}$ \\
\hline Awareness of birth preparedness $(n=680)$ & 480 & 70.6 \\
\hline Key danger signs during pregnancy & & \\
Severe vaginal bleeding $(n=744)$ & 360 & 48.8 \\
Swollen hands and face $(n=732)$ & 376 & 51.4 \\
Blurred vision $(n=740)$ & 320 & 43.2 \\
\hline Key danger signs during labor and childbirth & & \\
Severe vaginal bleeding $(n=756)$ & 444 & 58.7 \\
Prolonged labor $(>12$ hours $)(n=756)$ & 396 & 52.4 \\
Convulsion $(n=748)$ & 260 & 34.8 \\
Retained placenta $(n=740)$ & 352 & 47.6 \\
\hline Key danger signs during postpartum period & & \\
Severe vaginal bleeding $(n=760)$ & 408 & 53.7 \\
Foul lochia $(n=744)$ & 244 & 32.8 \\
High fever $(n=752)$ & 356 & 47.3 \\
\hline Key danger signs in newborn & & \\
Convulsions/spasms/rigidity $(n=748)$ & 312 & 41.7 \\
Difficulty/fast breathing $(n=748)$ & 372 & 49.7 \\
Very small baby $(n=740)$ & 308 & 41.6 \\
Lethargy/unconsciousness $(n=736)$ & 160 & 21.7 \\
\hline
\end{tabular}

seek care, delays in reaching care, and delays in receiving care [7]. These delays have many causes, including logistical and financial concerns, unsupportive policies, and gaps in services, as well as inadequate community and family awareness and knowledge about maternal and newborn health issues [2]. This study focuses on the individual woman's awareness of BP/CR and her intention/behavior toward eliminating delay when deciding to seek care.

The rural population of Nigeria in 2008 was put at $52 \%$ of the total [8]. There was a slight preponderance of respondents in this study residing in rural areas. About 50\% of women in this study had hospital delivery. Women who resided in urban areas were more likely to deliver in the hospital than those who resided in rural areas $(P<0.0001)$. This is to be expected because in Nigeria, the inverse care law operates. Provision of social amenities, including medical care, is concentrated in urban centers. According to the Nigeria demographic and health survey, $66 \%$ of Nigerian women deliver at home [9]. This is a dangerous trend that needs urgent attention, if the prevailing high maternal mortality and morbidity in the country is to be reversed. None of the women who delivered outside the hospital, in this study, received skilled attention. As seen in this study, women experienced emergency situations in the last pregnancy from reported danger signs that needed skilled intervention, such as prolonged labor, stillbirths, and severe vaginal bleeding after delivery. Maternal mortality resulting from the reported danger signs is beyond the scope of this study. Women who were in labor for more than 24 hours were more likely to undergo caesarean section than those who were in labor for less than 12 hours. Also, women who were in labor for more than 24 hours were more likely to notice difficult/fast breathing in their babies than those who were in labor for 12 to 24 hours. These were situations needing skilled attendance, so as to reduce morbidity and mortality in mother and baby.

Distance was an issue in seeking skilled attention, with up to half of the women having to travel up to $2 \mathrm{~km}$ or more to reach the nearest hospital. In a Nigerian study, $41 \%$ of the mothers who did not deliver in hospital explained that they could not afford the hospital bill, and $31 \%$ said they had transportation challenges [10]. The commonest means of transport in the last confinement was the motorcycle. We have shown in a previous study that this is a dangerous means of transportation for pregnant women, because the risk of serious morbidity following an accident is high [11]. A study from Nepal showed that a distance of more than one hour to the maternity hospital was statistically associated with an increased risk of home delivery [12].

The awareness of the concept of birth preparedness in this study was unexpectedly high. This is because the goaloriented interventions of focused antenatal care [13], which include BP/CR, are yet to be implemented in the Cross River State maternity services. Pregnant women are cared for on the basis of risk assessment in the traditional approach to antenatal care [3]. They are not usually counseled on the importance of recognizing danger signs, saving money for childbirth, and identifying a means of transport before delivery, among other issues of BP/CR matrix. That is why there is a disparity between awareness of the concept of birth preparedness and knowledge of specific danger signs in pregnancy, labor, and after childbirth. The knowledge of danger signs was rated to be poor in this study. Logistic regression analysis showed that educational status was the best predictor of awareness of the concept of birth preparedness. However, there was no association between awareness of birth preparedness and place of residence. Contrary to expectation, place of residence (urban or rural) was not a good predictor of awareness of birth preparedness. This is because educational status was the best predictor of awareness of birth preparedness, and the more educated women usually reside in the urban areas. Parity was a better predictor of knowledge of severe vaginal bleeding as a key danger sign during pregnancy than educational level. This can be explained by the fact that severe vaginal bleeding was a reported danger sign by women in the last pregnancy, and this experience was related more to parity than educational status.

In order for awareness of BP/CR to result in improved access to skilled attendance, there has to be action plan and service use. The type of action plan undertaken by women in preparation for childbirth will depend on right intention and appropriate behavior. Although this study showed that intention and plan to use maternity services were positive; educational level, marital status and parity were not good predictors of intention and behavior, especially regarding plan to attend at least four ANC visits with a skilled provider. This is an unfortunate finding as studies have shown that women who attend ANC are more likely to deliver in hospital [12]. Also, about $20 \%$ of women in this study experienced emergency situations in the last confinement that needed skilled intervention. However, none of the demographic 
TABLE 5: Complication readiness: service use and planning actions.

\begin{tabular}{lcc}
\hline Intention and behavior & Frequency & Percentage (\%) \\
\hline Plan to attend at least 4 ANC visits with skilled provider $(n=696)$ & 484 & 69.5 \\
\hline Plan to attend first ANC with skilled provider in first trimester $(n=680)$ & 484 & 71.2 \\
\hline Plan to give birth with skilled attendant $(n=732)$ & 580 & 79.2 \\
\hline Plan to save money for childbirth $(n=704)$ & 564 & 80.1 \\
\hline Plan to identify mode of transport to place of childbirth $(n=776)$ & 648 & 83.5 \\
\hline Knowledge of availability of community support systems $(n=736)$ & & 20.1 \\
$\quad$ Financial support system & 148 & 23.9 \\
Transport system & 176 & 3.3 \\
Blood donor system & 24 & \\
\hline
\end{tabular}

variables analyzed was associated with a significant intention to seek skilled attendance in future pregnancies. Awareness of birth preparedness was associated with a plan to identify a mode of transport to the place of childbirth before onset of labor. Transportation is a challenge in Nigeria, especially to pregnant women $[10,11]$. Road networks are poor in many urban areas and virtually nonexistent in rural areas. In addition, the transport system is inefficient and not always available when needed. That is why the establishment of a community support system with regard to transportation is a desirable measure to assist pregnant women, especially when an emergency arises. Unfortunately, knowledge of such support system in the community was very poor. Financial constraint in Nigeria is a major obstacle to accessing skilled attendance in pregnancy $[10,14]$. It is therefore appropriate for pregnant women to save money for childbirth and to be able to access emergency funds when needed. Parity was a highly significant predictor of planning to save money followed by awareness of birth preparedness. This finding may be related to past experience of danger signs in pregnancy and childbirth. Also, intention to save money was associated with knowledge of community financial support system. This is a step in the right direction and should be encouraged. The existence of community-level systems to provide emergency funds, transport, and blood donors, is vital in promoting maternal and newborn survival [6]. Community leadership therefore has an important role to play in removing barriers in deciding to seek care and improving access to a skilled care provider/attendant for women and their newborn babies. An emergency response system must be put in place and made known to the public. If women living in a community are ignorant of the existence of these emergency response systems, then they are unlikely to use and benefit from them. Also a system of identifying pregnant women through community-based health promoters will ensure that support/help is given when needed.

\section{Conclusion}

Although awareness of the concept of birth preparedness was high, recognition of key danger signs in pregnancy was poor. Proportion of births attended to by skilled attendant was low. Educational level, marital status, and parity were not good predictors of intention to attend at least four ANC visits with a skilled provider. The knowledge of available community support systems was very poor.

Based on these findings, it is recommended that

(i) birth preparedness and complication readiness should be made an integral part of maternal and child health services in the state, to enable women to recognize danger signs and access a skilled caregiver in pregnancy;

(ii) an emergency response system at the community level to provide emergency funds, transport, and blood donors must be put in place and made known to the public.

It is believed that with the removal of delays in decision to seek care and timely access to skilled attendance, the prevailing high maternal/infant morbidity and mortality in Nigeria can be reduced to acceptable limits.

\section{Conflict of Interests}

The authors report no conflict of interests in this work.

\section{References}

[1] Improving Safe Motherhood through Shared Responsibility and Collective Action. The Maternal and Neonatal Health Program Accomplishments and Results, Jhpiego, Baltimore, Md, USA, 2003.

[2] Birth Preparedness and Complication Readiness: A Matrix of Shared Responsibilities, Maternal and Neonatal Health Program, Baltimore, Md, USA, 2001.

[3] JHPIEGO Trainer News. Focused Antenatal Care; Planning and Providing Care During Pregnancy-A Maternal and Neonatal Health Program Best Practice, 2003.

[4] WHO/UNFPA/UNICEF/World Bank, Reduction of Maternal Mortality: A Joint Statement, WHO, Geneva, Switzerland, 1999.

[5] M. McDonagh, "Is antenatal care effective in reducing maternal morbidity and mortality?" Health Policy and Planning, vol. 11, no. 1, pp. 1-15, 1996.

[6] R. C. Del Barco, Ed., Monitoring Birth Preparedness and Complication Readiness. Tools and Indicators for Maternal and Newborn Health, Jhpiego, Baltimore, Md, USA, 2004. 
[7] S. Thaddeus and D. Maine, "Too far to walk: maternal mortality in context," Social Science and Medicine, vol. 38, no. 8, pp. 1091-1110, 1994.

[8] United Nations Population Division, http://www.un.org/esa/ population/unpop.htm.

[9] National Population Commission (NPC), Federal Republic of Nigeria and ORC Macro, Nigeria Demographic and Health Survey 2003, NPC and ORC Macro, Calverton, Md, USA, 2004.

[10] R. B. Fajemilehin, "Factors influencing high rate of 'bornbefore-arrival' babies in Nigeria-a case control study in Ogbomosho," International Journal of Nursing Studies, vol. 28, no. 1, pp. 13-18, 1991.

[11] E. I. Ekanem, S. J. Etuk, A. D. Ekanem, and J. E. Ekabua., "The impact of motorcycle accidents on the obstetric population in Calabar, Nigeria," Tropical Journal of Obstetrics and Gynaecology, vol. 22, no. 2, pp. 164-167, 2005.

[12] R. R. Wagle, S. Sabroe, and B. B. Nielsen, "Socioeconomic and physical distance to the maternity hospital as predictors for place of delivery: an observation study from Nepal," BMC Pregnancy and Childbirth, vol. 4, article 8, 2004.

[13] Maternal Neonatal Health: Focused Antenatal Care: Planning and Providing Care During Pregnancy. Program Brief March 2004.

[14] C. C. Ekwempu, D. Maine, M. B. Olorukoba, E. S. Essien, and M. N. Kisseka, "Structural adjustment and health in Africa," The Lancet, vol. 336, no. 8706, pp. 56-57, 1990. 


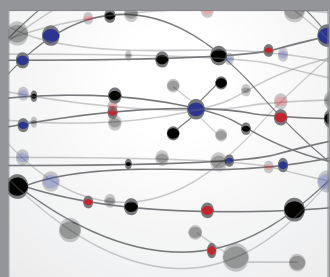

The Scientific World Journal
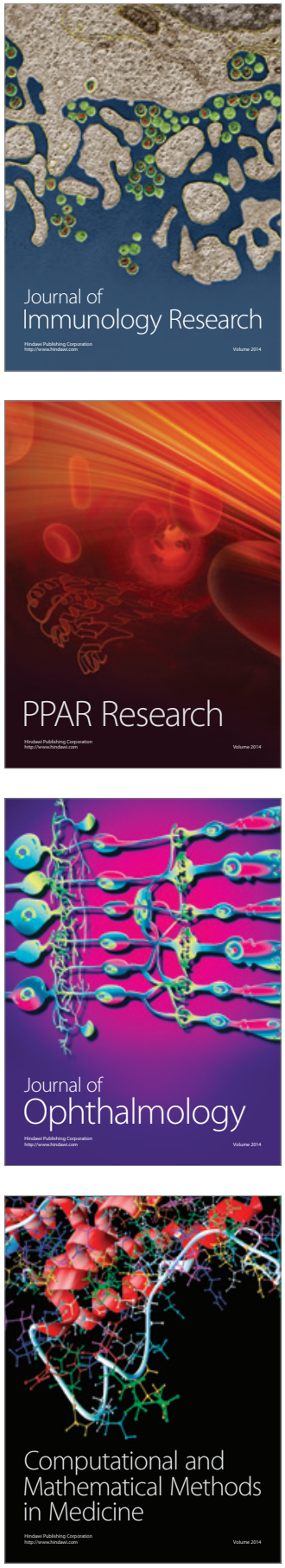

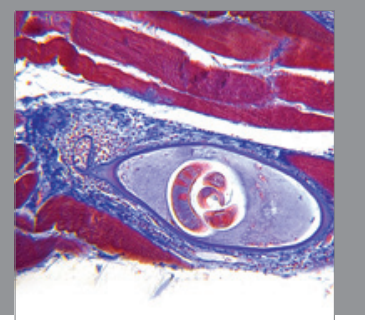

Gastroenterology

Research and Practice
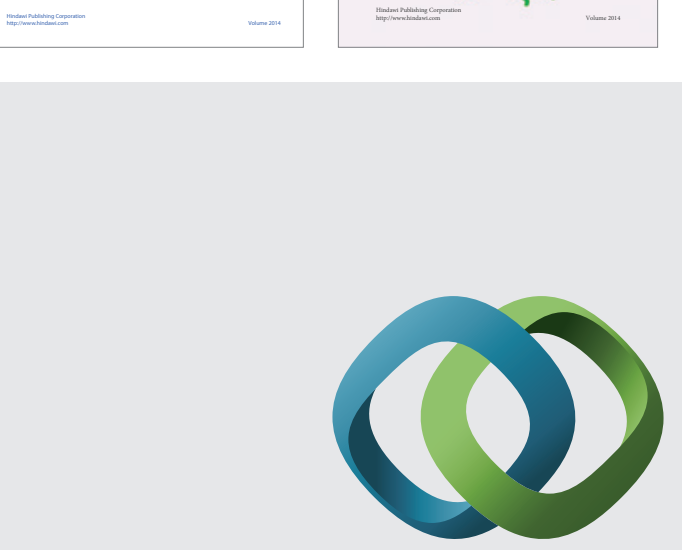

\section{Hindawi}

Submit your manuscripts at

http://www.hindawi.com
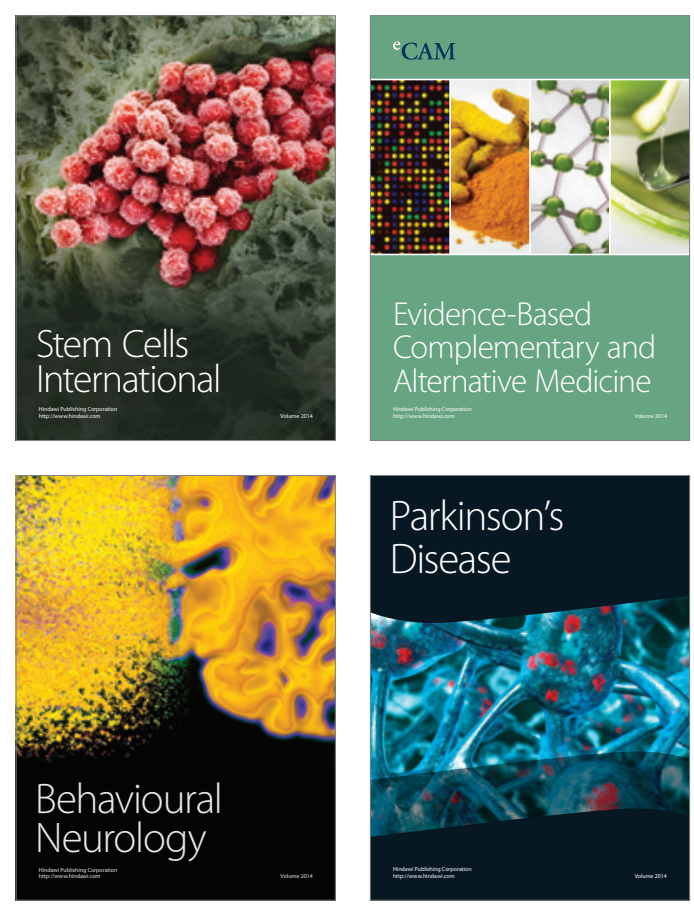

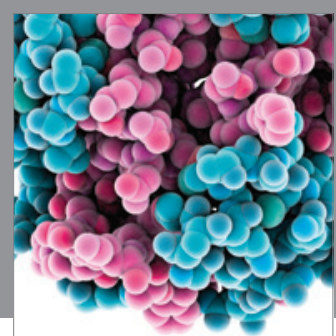

Journal of
Diabetes Research

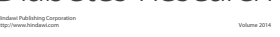

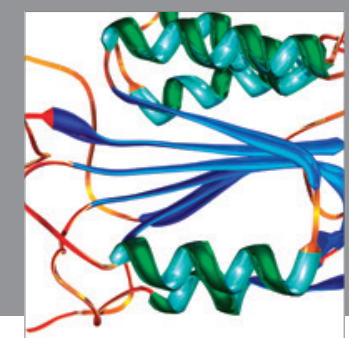

Disease Markers
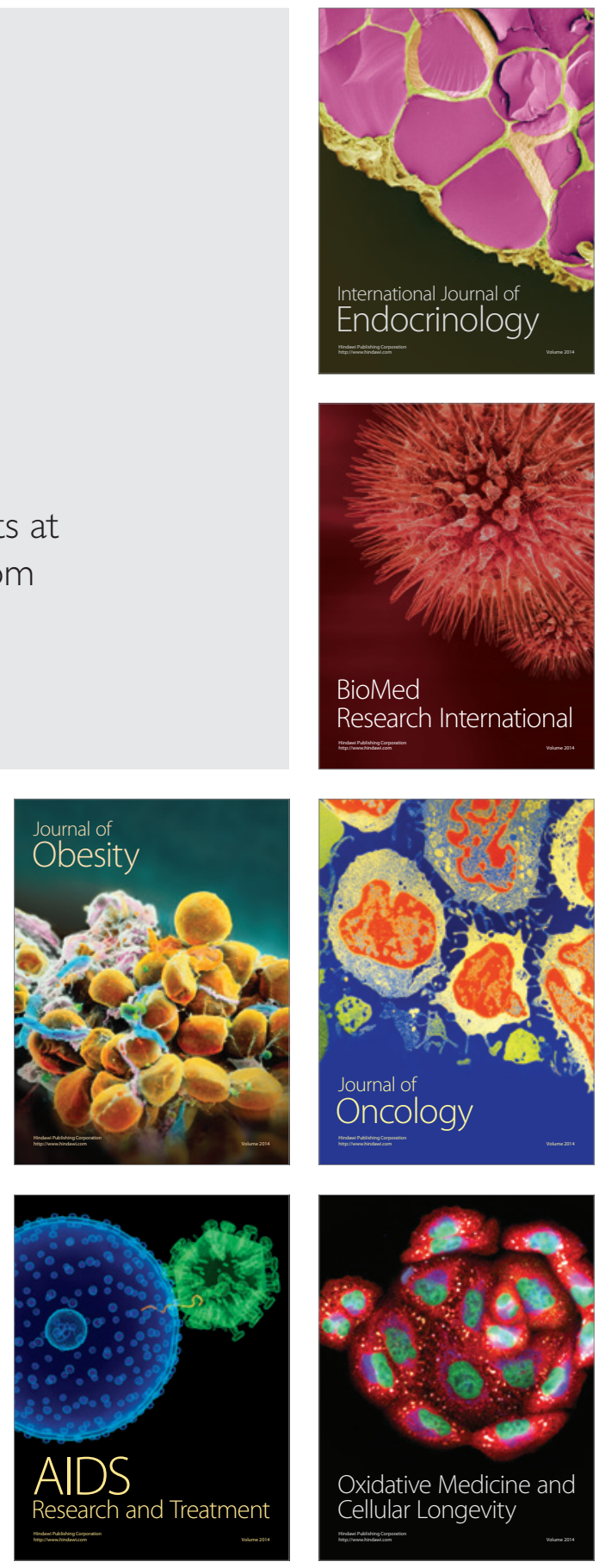